\title{
Interface for a Four-Sector Mass Spectrometer with a Dual-Purpose Collision Cell: High Transmission at Low to Intermediate Energies
}

\author{
Xueheng Cheng, Zhuchun Wu, and Catherine Fenselau \\ Department of Chemistry and Biochemistry, University of Maryland Baltimore County, \\ Baltimore, Maryland, USA \\ Morio Ishihara \\ JEOL, Ltd., Akishima, Tokyo, Japan
}

Brian D. Musselman

JEOL USA Inc., Peabody, Massachusetts, USA

A new interface system that consists of an ion decelerator, a floating collision cell-chemical ionization ion source, and an ion extractor was designed and installed in the third field-free region of a four-sector tandem mass spectrometer. Important features include the use of cylindrical deceleration lenses and an extraction lens assembly. This new design was found to provide enhancement of ion transmission at low to intermediate ion kinetic energies ( $3 \mathrm{eV}$ to $1 \mathrm{keV}$ ) compared with the standard collision cell design. Collision-induced dissociation experiments from $3 \mathrm{eV}$ to $10 \mathrm{keV}$ and ion-molecule reactions of mass-selected ions can be performed conveniently. A second, grounded, collision cell is located after the extraction lenses, which allows $\mathrm{MS}^{4}$ experiments to be carried out via the normal linked (B/E) scan function in MS2. Incorporation of chemical ionization capability into the electrically isolated collision cell makes it possible to carry out neutralization chemical-reionization mass spectrometry. (J Am Soc Mass Spectrom 1995, 6, 175-186)

$\mathrm{R}$ ecent progress in generating ions of large biomolecules in the gas phase without fragmentation has greatly enhanced the utility of mass spectrometry in the biological and life sciences. The structural determination of biomolecules by mass spectrometry usually involves the technique of tandem mass spectrometry in which the precursor ion is selected by the first stage mass spectrometer, activated by collision-induced dissociation (CID), and the ionic fragments are analyzed by the second stage mass spectrometer. Structural information then can be deduced from an analysis of the masses of the fragment ions. Alternative methods of activation are under investigation to provide more efficient fragmentation and more selective fragmentation. These methods include the use of photons [1], electrons [2], surfaces [3], and thermochemical reactions $[4,5]$. Thermochemical reactions designed to promote fragmentation of biopoly-

Address reprint requests to Catherine Fenselau, Department of Chemistry and Biochemiostry, University of Maryland Baltimore County, 5401 Wilkens Avenue, Baltimore, MD 21228. mers, and also some ion molecule reactions carried out to obtain physicochemical characterization of peptides [6], require a range of controlled kinetic energies provided most readily by beam mass spectrometers such as the four-sector instrument under discussion.

We have developed a series of tandem mass spectrometry interfaces for a four-sector tandem mass spectrometer toward the goals of providing ions with $\mathrm{ki}$ netic energies across a wide range of values, enhancing transmission in the low to mid kinetic energy range, and incorporating the function of chemical ionization into the collision cell $[4,5,7]$. Our target analytes are heavier ions ( $>1000 \mathrm{u}$ ) produced by desorption techniques such as fast-atom bombardment. This paper describes the features and performance of a new tandem mass spectrometry interface-collision cell assembly. Several types of experiments also are reported that are facilitated with this interface: CID over a range of collision energies from $3 \mathrm{eV}$ to $10 \mathrm{keV}$, ion-molecule reactions of mass-selected ions; a novel experiment that permits determination of $\mathrm{MS}^{4}$ product ion spectra, and neutralization-chemical reionization mass spectrometry (NCRMS). 


\section{The New Tandem Mass Spectrometry Interface}

Deceleration of ions that move with kilovolt energies is not trivial and has been a goal of instrumentalists for many years [8-19]. Many studies have been carried out in hybrid configuration instruments (typically $B E q Q$ ), where the high energy ions generated from a sector mass spectrometer are decelerated, refocused, and injected into devices like a quadrupole $[9,12,13$, 16], hexapole [11], octapole [15], or drift cell [14]. A few groups have addressed the problem of deceleration for collisions in four-sector instruments, experimentally $[10,17,19]$ or theoretically [18]. McLafferty et al. [10] introduced a three-element deceleration lens into the interface in an early four-sector instrument. Our design differs from that benchmark effort in several ways: Our three retarding lenses are cylindrical; our collision cell can be floated electrically; the collision cell is followed by a lens assembly that extracts and refocuses ions formed there. Recently $\mathrm{Yu}$ and Martin [19] reported the use of a three-element Einzel lens to improve deceleration on a standard JEOL interface; they also added extraction lens.

In the present work, the decelerated ions are refocused, reaccelerated, and injected into the second double-focusing sector mass spectrometer where both instruments are operated at $10 \mathrm{kV}$. The lens system for this interface (Figure 1b) uses tubular-shaped lens elements and is designed to achieve enhanced ion transmission at low energies relative to that available at high energies. Our lens is optimized outside the range calculated by Harting and Read [8] (33:1), and this work, along with that of Yu and Martin [19], shows it is possible to have efficient ion transmission at considerably higher deceleration ratios.

The tandem mass spectrometry interface of the JEOL HX110/HX110 (Peabody, MA) four-sector mass spectrometer (EBEB geometry), located in the third field- free region (FFR), was originally designed to achieve high transmission of ions with kilovolt kinetic energies (Figure 1a). The collision cell is electrically isolated from instrumental ground and therefore can be operated either at ground or at potentials that range from $0 \mathrm{eV}$ to $10 \mathrm{keV}$. (In our laboratory, it is typically operated at $4 \mathrm{keV}$, the so-called floated condition, for regular CID experiments to obtain better transmission and resolution of low mass ions.) The ion beam from MS1 can be refocused at any point near the source slit of MS2 by the electrostatic quadrupole lens doublet (QPD) [20]. The new tandem mass spectrometry interface includes the following modifications (Figure 1b) relative to the standard interface (Figure 1a): (1) the retarding lens is replaced by a set of three cylindricalshaped deceleration lenses; (2) the acceleration lens is replaced by a set of three extraction lenses; (3) the collision cell is modified so that both standard CID and chemical ionization experiments can be done with the same cell. In addition, a grounded collision cell can be placed between the extraction lenses and the second electric sector. The extraction lens design is similar to the lens assembly used in the standard JEOL electron ionization-chemical ionization (EI/CI) ion source. Because this lens was designed to extract ions created in the ion source, it also can be used to extract effectively the dissociation products generated within the collision cell, when it is operated at or near the normal acceleration potential of MS1.

A computer program ELECTRA, which is based on a charge density method [21] and the Runge-Kutta method, was used in this ion optical design [18]. By using ELECTRA one can calculate ion trajectories in the two-dimensional, cylindrically symmetric three-dimensional, and general three-dimensional spaces. In cases where simple initial conditions are used to describe the motion of the ions, one can determine the optimum lens potential for the objective of the lens [22]. In the present case, however, the optimum lens
Figure 1. Schematic diagram of (a) the previous and (b) the new tandem mass spectrometry interface for the four-sector tandem instrument.

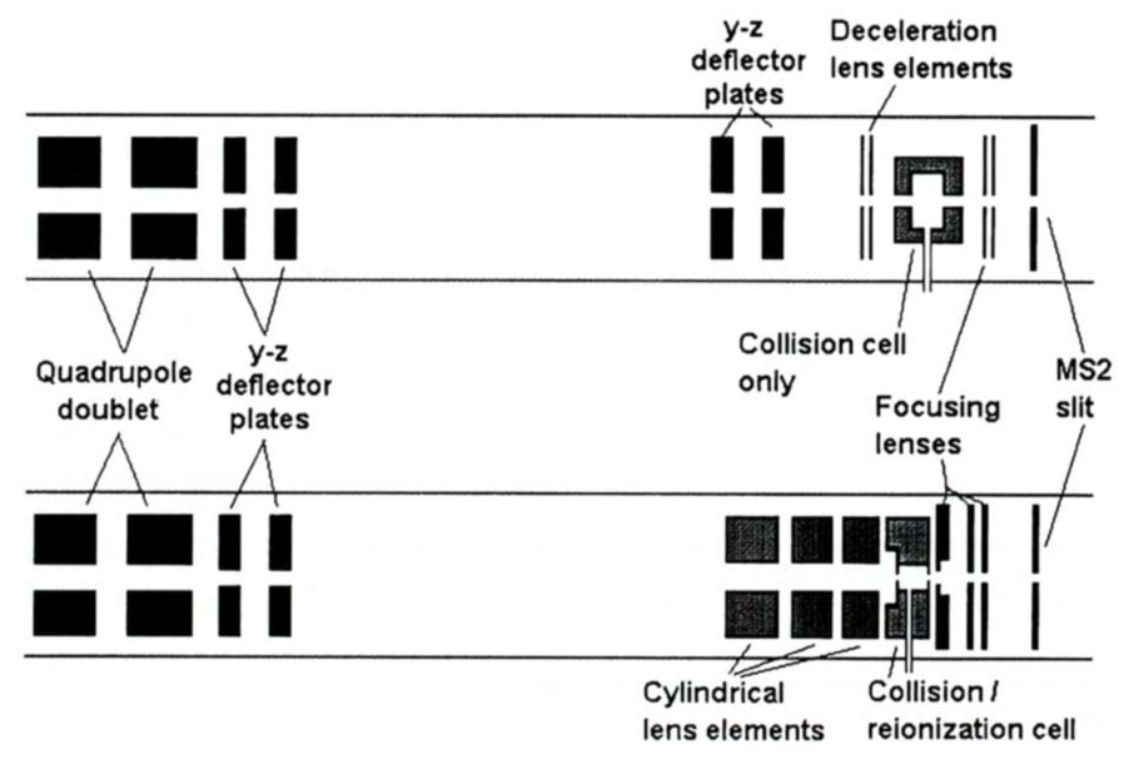


potential depends on many parameters, such as the initial conditions of ion formation in the ion source, extraction optics of the ion source, ion optics of MS1, setting of the quadrupole lens doublet in the interface, reaction mechanism of CID, and the ion acceptance of MS2. Accordingly it was practically impossible to explicitly determine the optimum lens potential and estimate the ion transmission by computer simulation alone. Therefore we experimentally determined the optimum lens potentials and we have measured the ion transmission.

\section{Ion Transmission}

The effect of ion kinetic energy on transmission by the new tandem mass spectrometry interface was evaluated by comparison with the results obtained for the regular interface under the same experimental conditions (resolution, slit settings, detector settings). The measurements were made by recording the relative signal intensities at a detector located before the tandem mass spectrometry interface at the double focusing point of MS1 and those at a detector located after the interface and at the double focusing point of MS2. The signal intensity of the second detector was optimized by adjusting the voltages of the several interface lenses for each kinetic energy studied. The kinetic energy of the ion is given by $E_{\text {lab }}=e\left[V_{\text {acc }}-V_{\text {coll }}\right]$, where $V_{\text {acc }}$ is the acceleration voltage of MS1 and $V_{\text {coll }}$ is the floating voltage of the collision cell (both regular and modified); the values of these voltages were determined by using a high voltage probe with an accuracy of $\pm 1 \mathrm{~V}$. Figure 2 shows the result of the transmission measurement for $m / z 1951$ cations generated from CsI by fast-atom bombardment (FAB). For either cell, the ion transmission is normalized to the highest value to remove factors due to any differences in detector sensitivity. The two interfaces give essentially the same ion transmission in the range of $E_{\mathrm{lab}}=1 \mathrm{keV}$ to $6 \mathrm{keV}$. Below $E_{\text {lab }}=1 \mathrm{keV}$, the new interface is superior in ion transmission. For the greater part of this low to intermediate energy region ( $3 \mathrm{eV}$ to $1 \mathrm{keV}$ ), the transmission for the new interface is roughly three to four times better than the regular interface relative to transmission at $6 \mathrm{keV}$.

The effect on ion transmission of the three cylindrical deceleration lenses in this new design was evaluated by first optimizing ion transmission at a given $E_{\text {lab }}$ and then setting the voltages of L1 and L2 to zero and readjusting $\mathrm{L3}$ (Figure $1 \mathrm{~b}$ ) and other voltages of the interface to reoptimize ion transmission. In this way, the two additional cylindrical deceleration lenses are found to enhance the ion transmission by $10 \%$ at $E_{\text {lab }}=1 \mathrm{keV}$. The contribution of L1 and L2 to the enhancement of ion transmission increases steadily as the $E_{\text {lab }}$ decreases and it amounts to about $200 \%$ at $E_{\text {lab }}=50-100 \mathrm{eV}$. The increase in transmission also is affected by the three extraction lenses located after the collision-chemical ionization (CI) ion source cell.

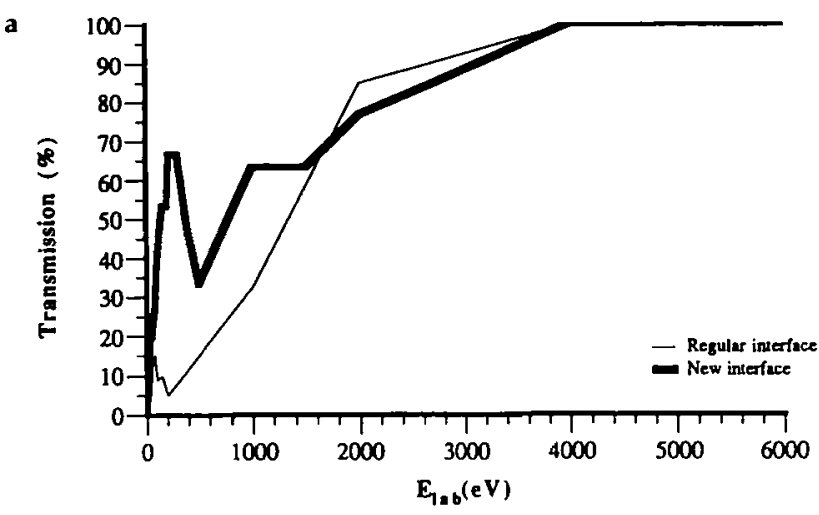

b

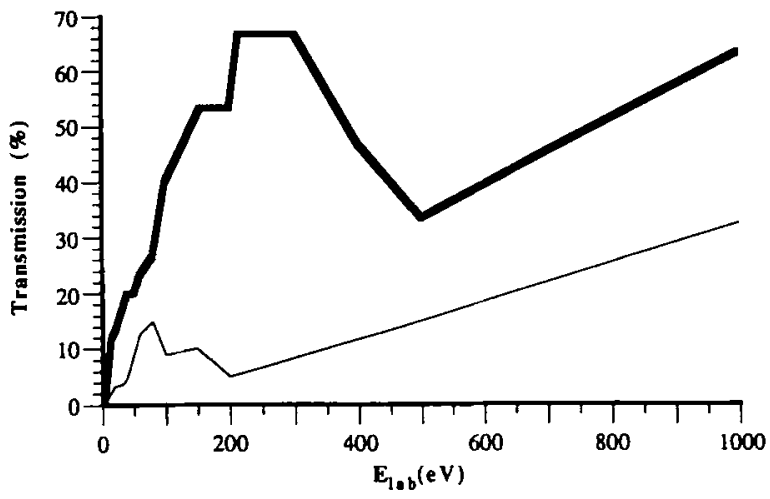

Figure 2. (a) Ion transmission as a function of kinetic energy for the previous tandem mass spectrometry interface and the new interface $\left(\mathrm{Cs}_{\mathrm{g}} \mathrm{I}_{7}^{+}, m / z 1951\right.$ was used). Transmissions values are normalized to the highest. (b) Expanded view of (a) in the low kinetic energy region.

However, the improvement in ion transmission is uneven and the greatest gain is around $E_{\text {lab }}=200-300$ $\mathrm{eV}$ (Figure 2b). The local minima and maxima seen in Figure 2 may reflect the interplay between the decreased ion transmission due to the divergence of the ion beam at low kinetic energies and the increased role of interface lenses in extracting and refocusing the ion beam at these low energies. In a typical setting, the three deceleration lenses have voltages progressively higher from L1 to L3, for example, 1.53, 2.08, and 2.50 $\mathrm{kV}$ when the collision cell is floated at $4 \mathrm{kV}$. No appreciable changes were observed with regard to kinetic energy spread.

\section{Collision-Induced Dissociation of Arginine-Containing Peptides at Different Collision Energies}

Because the fragment ions from CID experiments provide information with regard to the structure of the precursor ion, a better understanding of the energy dependence of the fragmentation process is important. With regard to peptides, high (kiloelectronvolt) and low $(<100-\mathrm{eV})$ energy CID have been studied extensively by using sector [23, 24], multiple quadrupole, 
and hybrid [25] instruments, respectively. It has been observed that kiloelectronvolt CID produces abundant $d_{n}, w_{n}$, and $v_{n}$ types of fragment ions (the nomenclature here is after Biemann [23]), which are derived from side-chain cleavages [24]. Those ions can be used to distinguish isomeric residues [26], but also can increase the complexity of the CID spectra. By using conditions employed for low energy CID, however, those side-chain cleavage ions are not observed even though the multiple collision conditions usually used can produce quite efficient fragmentation for peptides up to $1000 \mathrm{u}$ [27]. The high energy requirement for the formation of side-chain cleavage ions is consistent with the notion that they are formed through charge-remote processes $[24,26,27]$.

Standard collision cells that have been produced for both sector and quadrupole-hybrid instruments have not been optimized for use at potentials in the energy region between $100 \mathrm{eV}$ and $1 \mathrm{keV}$, where the onset for production of side-chain-specific cleavage products occurs, and this range has not been well investigated. By using a four-sector instrument, Martin et al. [28] reported that the $d_{10} / a_{10}$ ion ratio for renin substrate tetradecapeptide, a peptide with arginine near the $\mathrm{N}$ terminal, decreases drastically when the collision energy goes below $1 \mathrm{keV}$ and that for $\beta$-lipotropin, a peptide with no strongly basic residues, $v_{8}$ and $w_{9}$ ions essentially disappear at $E_{\text {lab }}$ below $2 \mathrm{keV}$. Alexander et al. [29] used a hybrid mass spectrometer to investigate the collision energy dependence of chargeremote fragmentations and concluded that collision energy of at least $200 \mathrm{eV}$ is required to observe these processes. By taking advantage of the increased ion transmission provided by the new interface in this intermediate energy region, we have studied the energy dependence of CID process for three peptides: renin substrate tetradecapeptide (DRVYIHPFHLLVYS, $\mathrm{MW}=1758 \mathrm{u}$ ), bradykinin (RPPGFSPFR, MW $=1060$ $\mathrm{u})$ and leucine enkephalin-arginine (YGGFLR, MW = $711 \mathrm{u})$. These sequences have arginine at the $\mathrm{N}$-terminal (renin substrate), the C-terminal (leucine enkephalin-arginine), and at both termini (bradykinin), and their molecular weights range from 711 to $1758 \mathrm{u}$. Figure 3 shows the CID spectra of renin substrate at $E_{\text {lab }}=6,1 \mathrm{keV}, 600,500,300$, and $100 \mathrm{eV}$, all at target gas pressures that attenuate the beam by $80 \%$. The precursor ion peaks are plotted off-scale so that the fragmentation patterns may be examined. The spectrum at $1 \mathrm{keV}$ (Figure $3 \mathrm{~b}$ ) is very similar to the one taken at $6 \mathrm{keV}$ (Figure 3a) in that the relative distribution of the product ions is consistent in each spectrum. In the spectra the $a_{n}$ and $d_{n}$ series of ions dominate due to the presence of arginine near the $N$-terminal. Most of the $d_{n}$ ions are not observed in the $E_{\text {lab }}=$ 600-500-eV spectra, except for the $d_{3}$ and $d_{11}$ ions that persist even at $100 \mathrm{eV}$ (see insert in Figure 3f for $d_{3}$ ion); at the same time, relative abundances of $b_{n}$ and $c_{n}$ ions increase as $E_{\text {lab }}$ is reduced. There are also subtle changes among $d_{n}$ ions. For example, the $d_{8}$ ions (cleavage in the side chain of phenylalanine) disappear between $1 \mathrm{keV}$ and $600 \mathrm{eV} ; d_{5}$ (isoleucine), $d_{10}$ (leucine), and $d_{12}$ (alanine) ions become undetectable between 600 and $500 \mathrm{eV}$. Similar features also are observed for the other two peptides studied, that is, (1) there is very little difference between CID spectra taken at 6 and $1 \mathrm{keV} ;(2)$ most of $d_{n}, w_{n}$, and $v_{n}$ ions are not observed below $E_{\text {lab }}=500 \mathrm{eV}$, whereas $b_{n}, c_{n}$, and $y_{n}$ type ions are enhanced; (3) some $d_{n}$ and $w_{n}$ ions persist down to $E_{\text {lab }}=100 \mathrm{eV}$. These persisting side-chain cleavage ions are either from residues with labile bonds $\left(d_{6}\right.$ and $w_{4}$ from serine residue in bradykinin) or in a position proximate to the arginine $\left(d_{3}\right.$ from valine in renin substrate tetradecapeptide and $w_{2}$ from leucine in leucine enkephalin-arginine). It is likely that those latter side-chain cleavage ions are not formed by a charge-remote process, but rather by charge-proximal processes because the residues with those side chains are next to the arginine, the most basic amino acid [30] on which the proton is most likely to be localized. The different energy at which the onset of side-chain fragmentation occurs in each molecule studied reflects the nature and position of these specific residues.

Earlier, Bordas-Nagy et al. [31] published high energy CID spectra of several peptides, which included renin substrate tetradecapeptide, and compared $\mathrm{He}$ and $\mathrm{Ar}$ as collision gases. They observed that Ar collision gas gave more abundant side-chain cleavage ions than $\mathrm{He}$ at $4-\mathrm{keV}$ collision energy. Interestingly, both the 6- and 1-keV He CID spectra of renin substrate acquired in this study are similar to the 4-keV Ar CID spectrum published by Bordas-Nagy et al., whereas the $600-\mathrm{eV}$ He CID spectrum reported here is similar to the earlier 4-keV He CID spectrum. These differences probably are due to the different instruments used in each of these studies.

\section{Neutralization-Chemical Reionization of Renin Substrate Tetradecapeptide}

Neutralization-reionization (NRMS) via electron transfer reagents has been studied extensively by a number of groups and it has been shown to be a powerful method for the study of structures of ions and properties of reactive neutral species [32]. In a previous publication [5], we showed the possibility of the use of proton transfer reagents to achieve neutralization and reionization and termed it neutralization-chemical reionization mass spectrometry (NCRMS). The method of NCRMS allows the use of the same collision cell and the same target gas to carry out both neutralization and reionization, and the process is well suited for ions generated from desorption and spray processes from which protonated molecular ions are formed. When the new interface was evaluated, we observed neutralization and chemical-reionization of renin substrate (MW $=1758$ ) by using methane as the neutralizationreionization gas. 


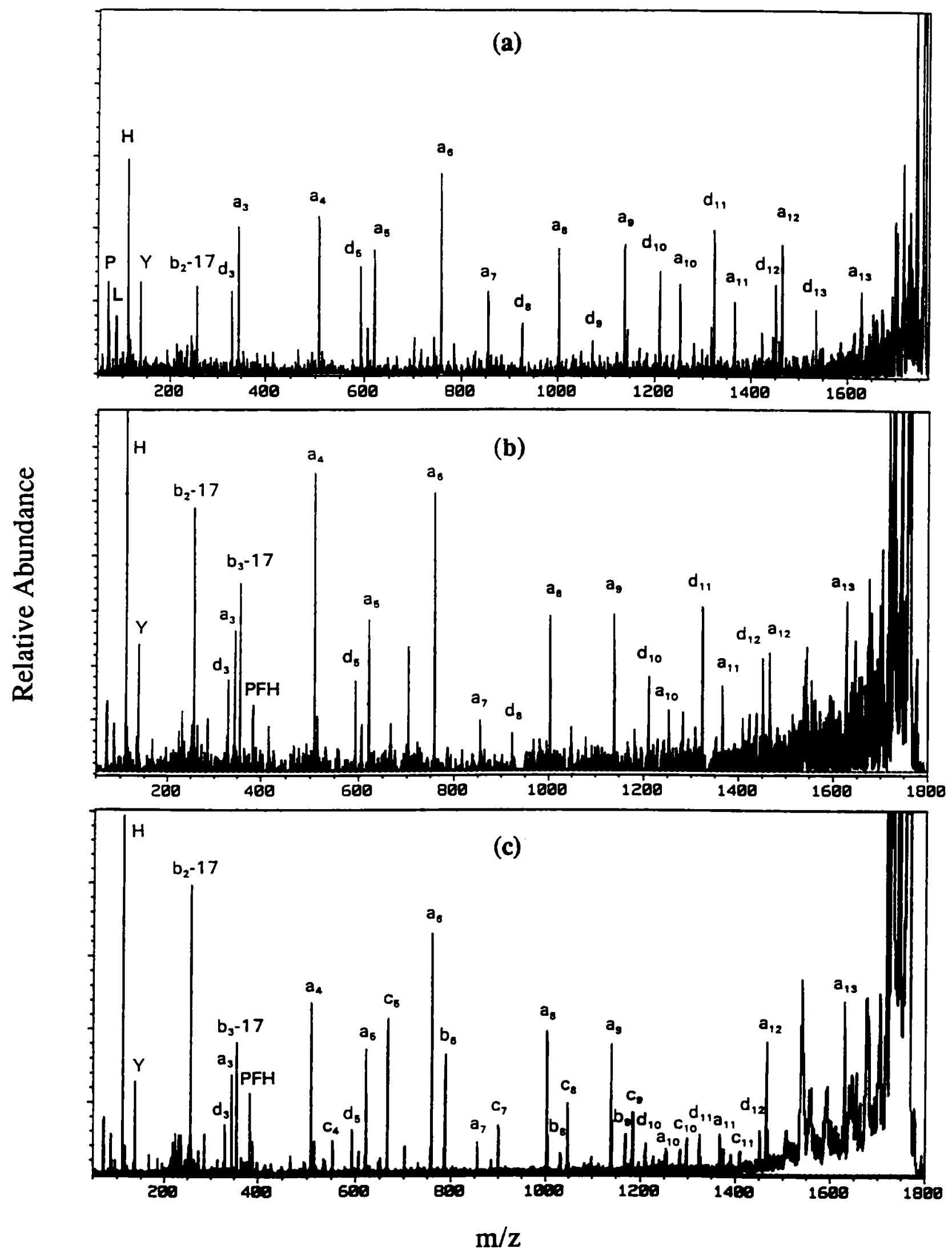

Figure 3. CID spectra of renin substrate tetradecapeptide with He as collision gas at $E_{\text {lab }}$ values of (a) $6 \mathrm{keV}$, (b) $1 \mathrm{keV}$, (c) $600 \mathrm{eV}$, (d) $500 \mathrm{eV}$, (e) $300 \mathrm{eV}$, and (f) $100 \mathrm{eV}$ (80\% attenuation of precursor ion beam; resolution $=1000$ ). 


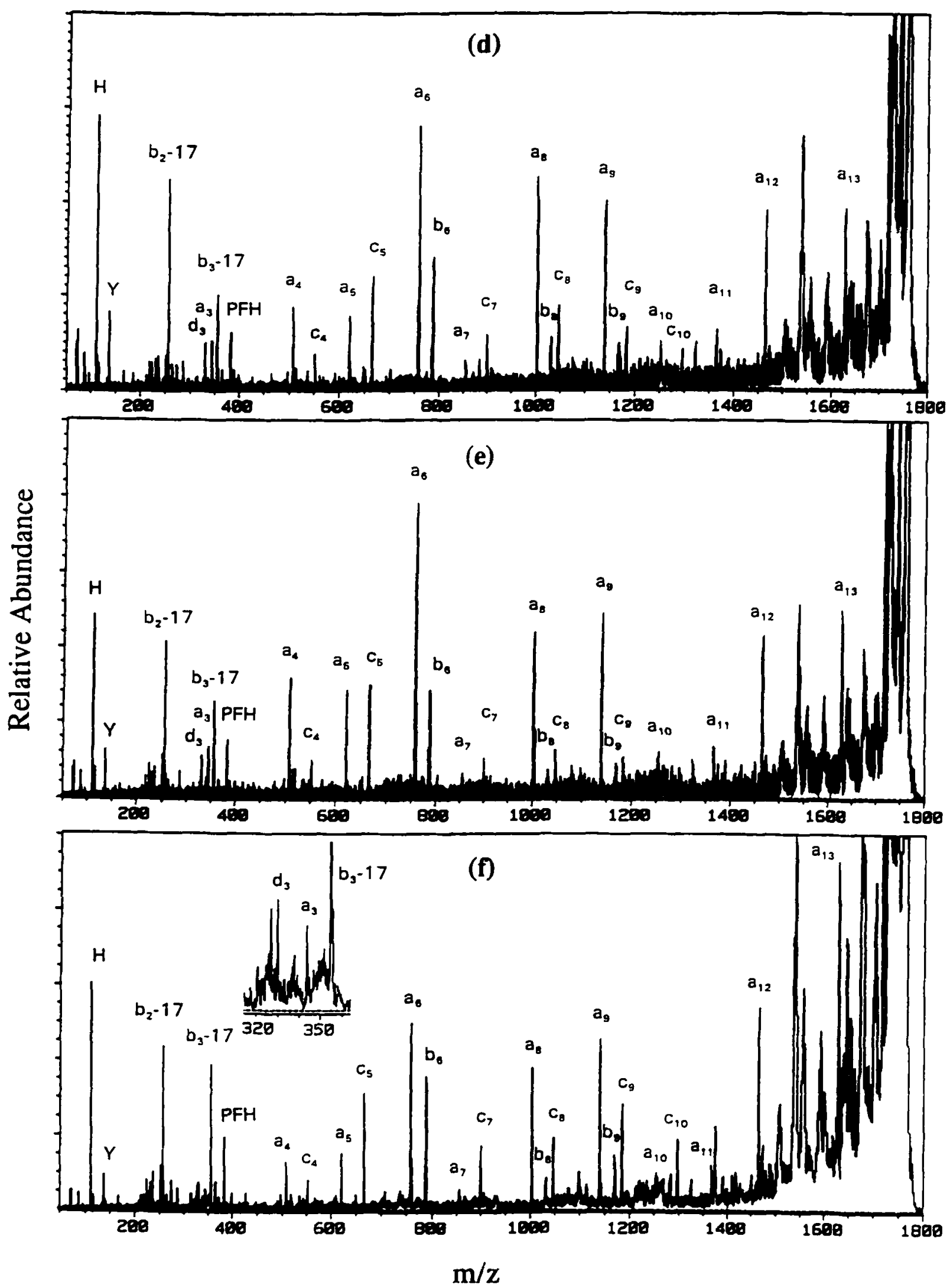

Figure 3. Continued. 
Spectra obtained by reactions with $\mathrm{CH}_{4}$ are shown in Figure 4. In spectrum $4 a$ the ions recorded are considered to be formed by transfer of protons from the peptides to $\mathrm{CH}_{4}$ (neutralization of the peptide). Proton or charge transfer in a collision complex from the arginine-containing peptide to $\mathrm{CH}_{4}$ would be highly endothermic, and alternative mechanisms are under consideration. Davis et al. [33] have suggested a mechanism analogous to charge stripping for proton transfer observed from a peptide to $\mathrm{NH}_{3}$ at collision

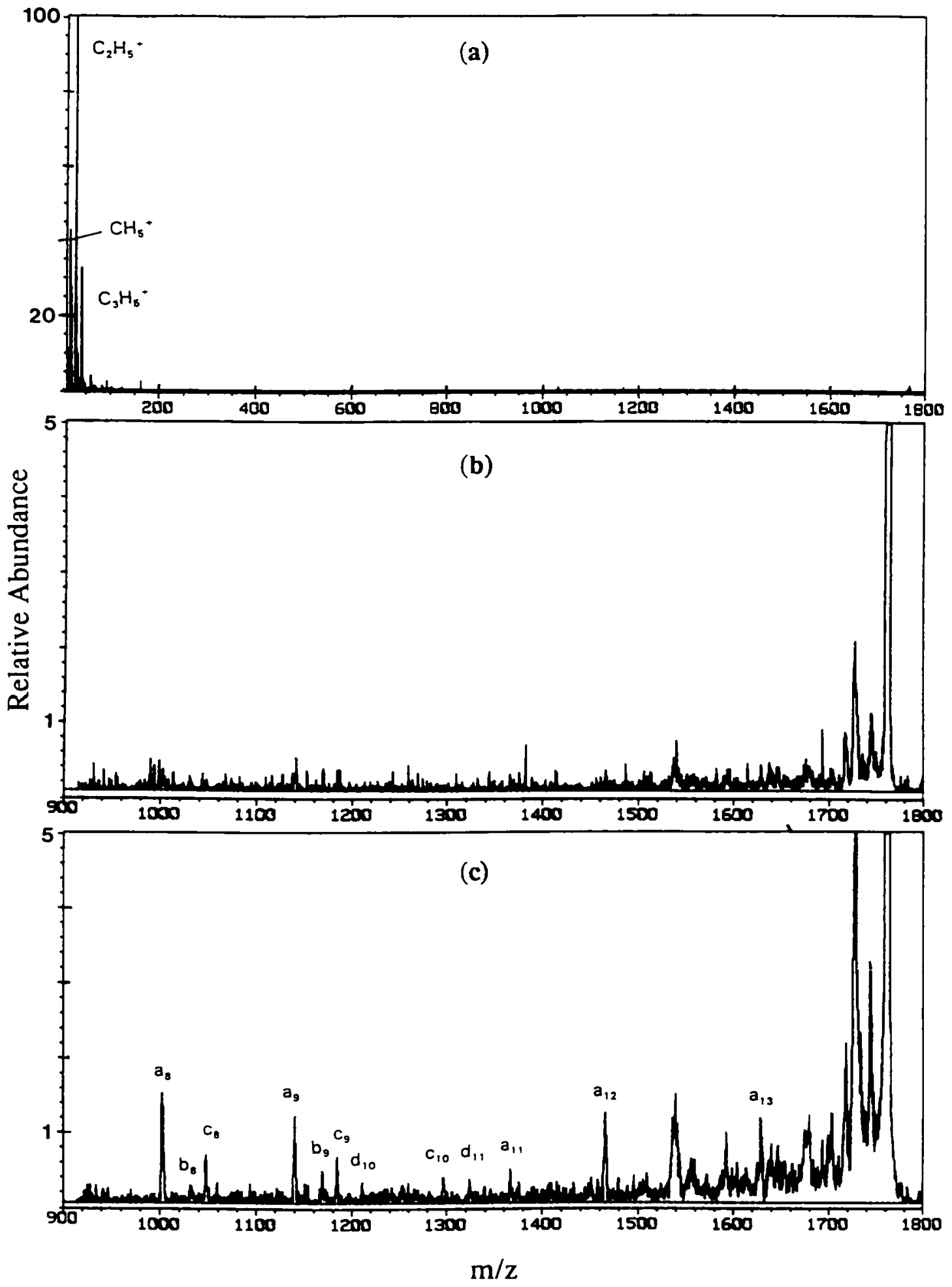

Figure 4. Product ion spectra for reactions of protonated renin substrate tetradecapeptide with $\mathrm{CH}_{4}, E_{\text {lab }}=50 \mathrm{eV}$. Nominal pressure of (a) $\mathrm{CH}_{4} 0.2$ torr, filament off; (b) $\mathrm{CH}_{4} 0.05$ torr, filament off; (c) $\mathrm{CH}_{4} 0.05$ torr, electron current $300 \mu \mathrm{A}$. 
energy too high to allow complex formation. Spectra $4 \mathrm{~b}$ and $\mathrm{c}$ were obtained at a lower pressure of $\mathrm{CH}_{4}$ with the electron beam in the dual collision-chemical ionization cell turned off and on, respectively. The latter condition can be seen to enhance production of fragment ions. Several interpretations are possible. One, chemical ionization of neutral fragments formed by CID, is less likely because all of the fragment ions observed comprise the same arginine-containing part of the molecule. The masses of the $c_{n}$ ions observed are not consistent with fragmentation by electron impact processes [34], that is, ionization by the electron beam. A third interpretation is that the increase in fragmentation is derived from exothermic chemical reionization of the peptides. The $d_{10}$ and $d_{11}$ ions are of particular interest because this experiment was carried out at $E_{\mathrm{lab}}=50 \mathrm{eV}$. In CID with $\mathrm{He}, d_{10}$ ions are not detected and $d_{11}$ ions are observed with very low intensity below $E_{\mathrm{lab}}=600 \mathrm{eV}$ (vide supra). The exothermicities for reionization of neutral renin substrate by $\mathrm{CH}_{5}^{+}$and $\mathrm{C}_{2} \mathrm{H}_{5}^{+}$(the most abundant ionic species in the collision cell when the filament is turned on) are estimated to be 120 and $90 \mathrm{kcal} / \mathrm{mol}$ or 5.2 and $3.9 \mathrm{eV}$, respectively, based on proton affinities (PA) of $132 \mathrm{kcal} / \mathrm{mol}$ for $\mathrm{CH}_{4}, 163 \mathrm{kcal} / \mathrm{mol}$ for $\mathrm{C}_{2} \mathrm{H}_{4}$ [35] and $\geq 255 \mathrm{kcal} / \mathrm{mol}$ estimated for renin substrate tetradecapeptide based on $\mathrm{PA}=245.2 \mathrm{kcal} / \mathrm{mol}$ for arginine [30] and increments for each additional residue [36]. These exothermicity values correspond to the center of mass collision energy $\left(E_{\mathrm{cm}}\right)$ for CID of renin substrate ions with $\mathrm{He}$ at $E_{\mathrm{lab}}=2.3$ and $1.7 \mathrm{keV}$, respectively. Thus the exothermicity of the reionization step is enough to cause the types of fragmentation that are typically achieved in high energy CID.

\section{MS $^{4}$ Experiments}

Multiple-stage mass spectrometry (MS" $n>2$ ) is a very useful technique for studies of internal energy deposition and fragmentation pathways [37,38] and has been used in structural mass spectrometry as well $[39,40] . \mathrm{MS}^{+}$and $\mathrm{MS}^{5}$ have been demonstrated in a four-sector tandem instrument with high energy CID [38]. In our previous $\mathrm{MS}^{3}$ experiment [40], successive CID was completed by using two collision cells located in the first and third FFR, respectively. By floating the second collision cell, sensitivity for low mass ions was enhanced. Now with another grounded collision cell located after the extraction lenses in the third FFR, $\mathrm{MS}^{4}$ has been carried out successfully.

The electrostatic sector is an energy analyzer whereas the magnetic sector separates ions with respect to their momentum-to-mass ratios. In a CID process via a sector instrument, all the product ions derived from the selected precursor have the same nominal velocity because momentum is conserved and changes in kinetic energy by loss to target molecules or conversion of internal energy are negligible. Thus the momentum-to-mass ratio is equivalent to the mass-tocharge ratio for these experiments. It is convenient to represent the scan scheme in a two-dimensional diagram (Figure 5) for tandem sector instruments, where one dimension is energy and the other is mass-tocharge ratio. A constant $B / E$ product ion scan is represented as a straight line with positive slope in this two-dimensional plot. In the $\mathrm{MS}^{4}$ experiments described here the first generation product ions, formed during CID in the first FFR collision cell, were selected by using $\operatorname{MS1}\left(E_{1} B_{1}\right)$ and transmitted to the second
Figure 5. Scheme for the scan function relationship between energy and mass analyzers that illustrates the scanning lines followed by the different $\mathrm{MS}^{4}$ experiments for which results are shown in Figures 6 (一) and Figure $7(\cdots)$.

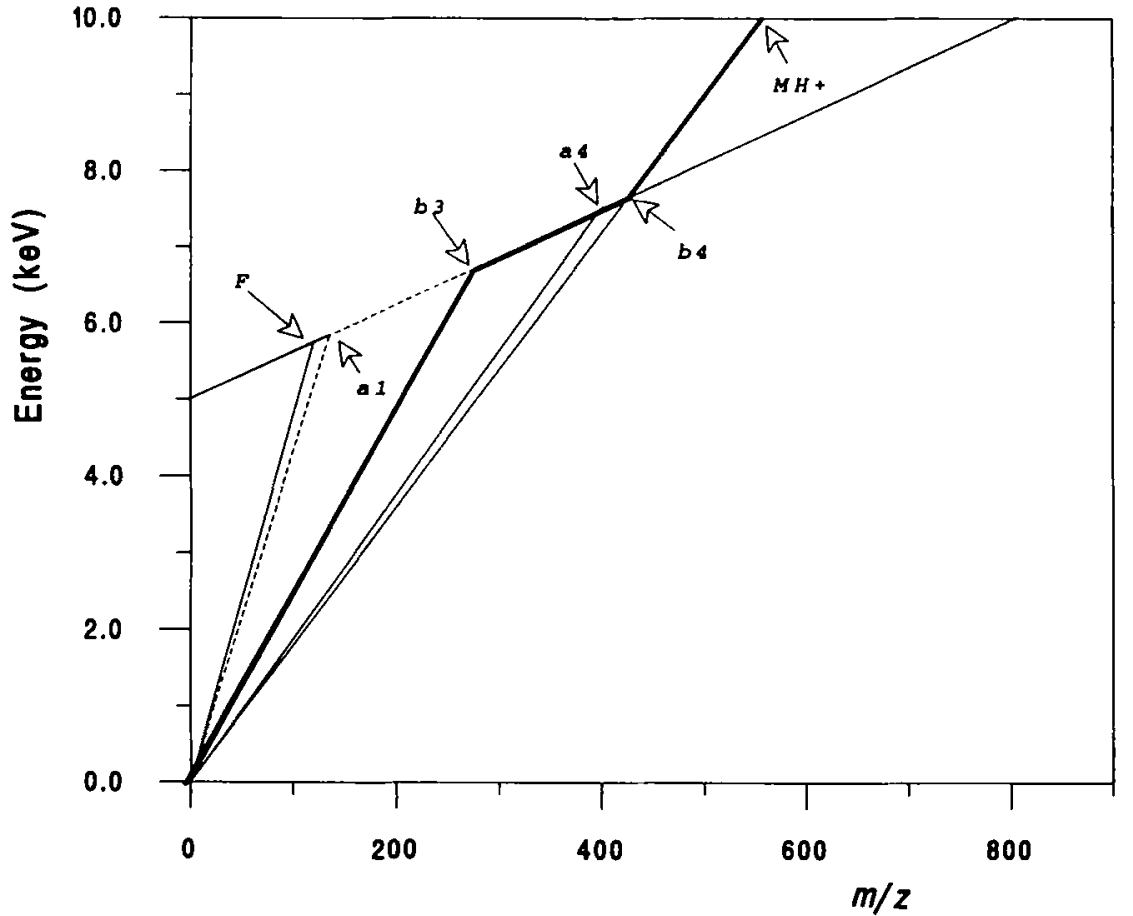




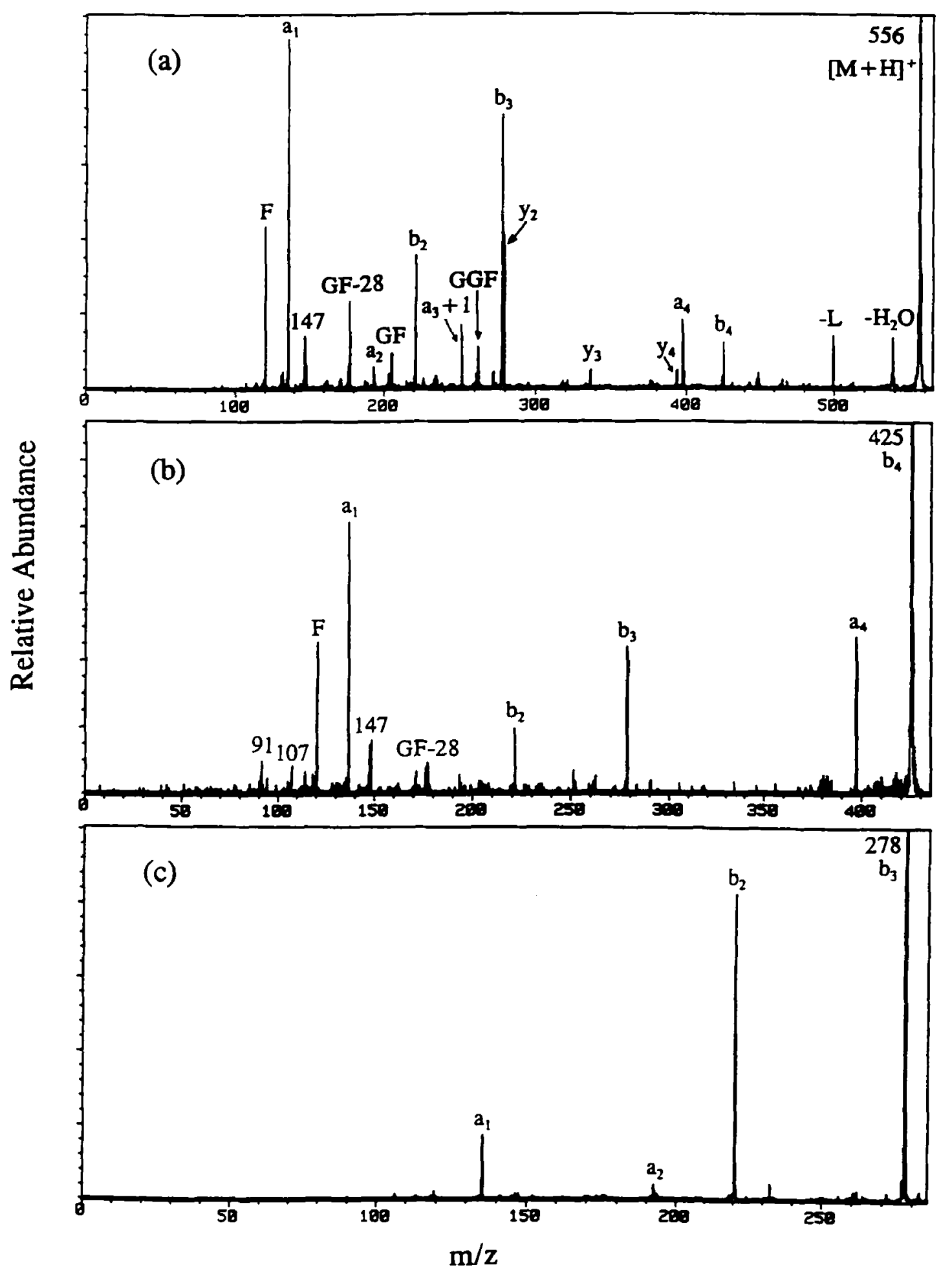

Figure 6. (a) Tandem mass spectrometry CID spectrum of leucine enkephalin. (b) CID product ion spectrum with the $b_{4}$ ion as the precursor; the sequential reaction scheme was $\mathrm{MH}^{+} \rightarrow b_{4} \rightarrow$ fragments; an $\mathrm{MS}^{3}$ experiment. (c) CID spectrum of $b_{3}$ ion derived from the $b_{4}$ ion in the sequential reaction $\mathrm{MH}^{+} \rightarrow b_{4} \rightarrow b_{3} \rightarrow$ fragments; an $\mathrm{MS}^{+}$experiment. 


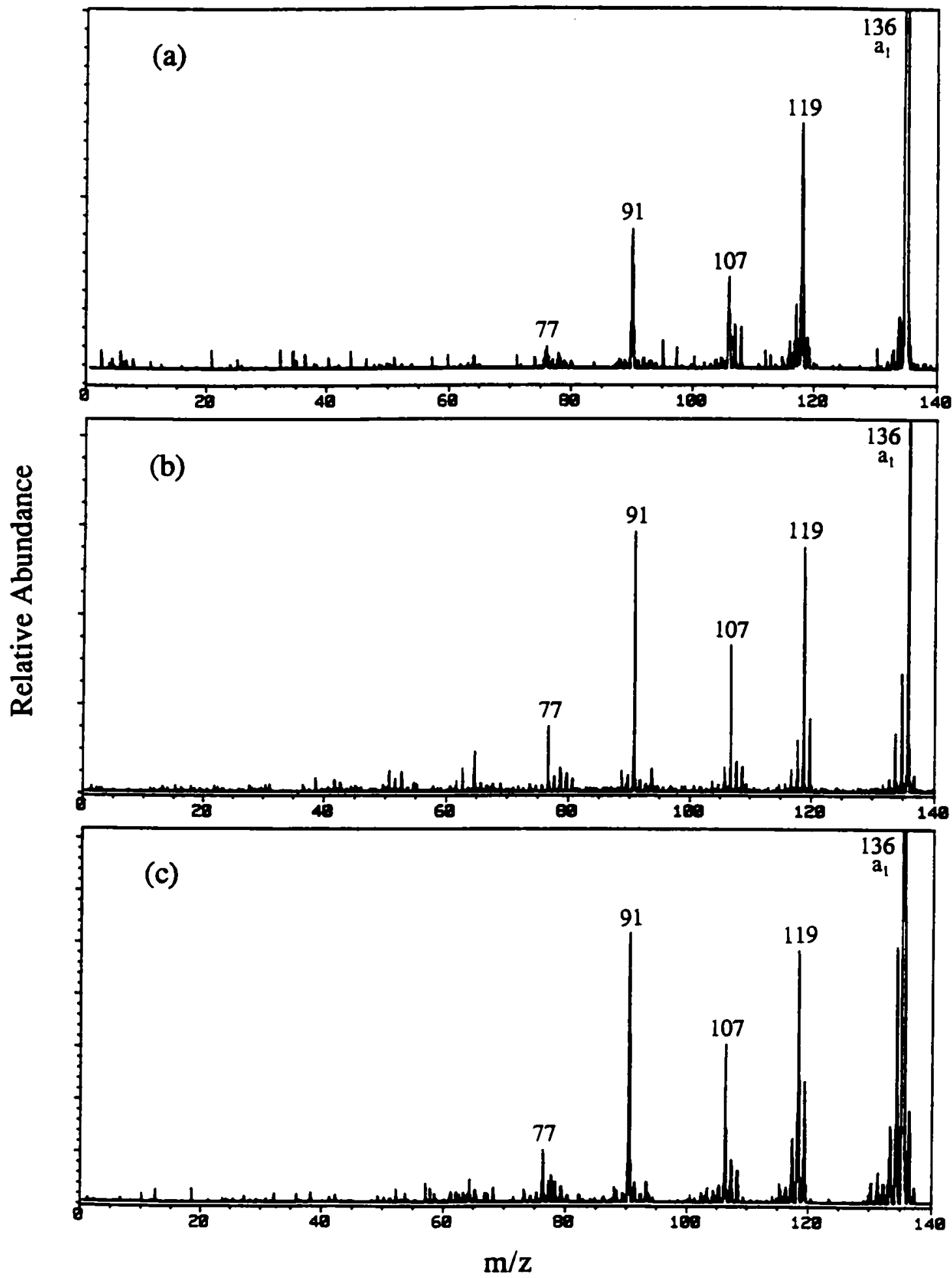

Figure 7. CID spectra of tyrosine immonium ions derived from leucine enkephalin by sequential reactions of $\mathrm{MH}^{+} \rightarrow a_{1} \rightarrow$ fragments in an $\mathrm{MS}^{3}$ experiment with (a) two collision cells located in the first and third FFR and (b) two collision cells both located in the third FFR. (c) CID spectrum of tyrosine immonium ions in the sequential reaction $\mathrm{MH}^{+} \rightarrow b_{4} \rightarrow a_{1} \rightarrow$ fragments in an $\mathrm{MS}^{4}$ experiment. 
collision cell in the third FFR of the instrument. The second generation product ions formed in the second collision cell were transmitted directly to the third collision cell without any mass or energy separation. The second collision cell was floated to $5 \mathrm{kV}$ above instrumental ground while the third collision cell was operated at ground potential. Thus, all of the second generation product ions formed in the second collision cell should have kinetic energy above $5 \mathrm{keV}$. Consequently, all of the third generation product ions formed in the third collision cell can be separated due to differences in their kinetic energies and mass-to-charge ratios by scanning the $\mathrm{MS} 2\left(\mathrm{E}_{2} \mathrm{~B}_{2}\right)$ instrument via the constant $B / E$ linked scan. We have collected the third generation product ion spectra via this method. The actual scan schemes in these $\mathrm{MS}^{4}$ experiments are described in Figure 5. Selectivity of precursor ions for the third generation product ions was expected to be poor (several units) and artifacts easily generated. Nonetheless, the advantage of this configuration is that it avoids the complexities of installation of a collision cell between the second $\mathrm{E}$ and $\mathrm{B}$ sectors to complete the additional step of CID.

Sequential reactions of leucine enkephalin in $\mathrm{MS}^{2}$, $\mathrm{MS}^{3}$, and $\mathrm{MS}^{4}$ experiments are shown in Figure 6. Reactions studied in these $\mathrm{MS}^{4}$ experiments are $\mathrm{MH}^{+}$ $\rightarrow b_{4} \rightarrow b_{3} \rightarrow$ fragments. No new ion dissociation pathways were identified in either the $\mathrm{MS}^{3}$ or $\mathrm{MS}^{4}$ experiments. The CID spectra of tyrosine immonium ions that originate from leucine enkephalin are shown in Figure 7. The sequential reaction $\mathrm{MH}^{+} \rightarrow a_{1} \rightarrow$ fragments was followed by using two different kinds of $\mathrm{MS}^{3}$ experiments. The first method involves the use of the first and second collision cells located in the first and third FFR (Figure 7a) to effect sequential CID processes, whereas the other uses the second and third collision cells, which are both located in the third FFR, with the second cell floated at $5 \mathrm{kV}$ and the third operated at ground potential (Figure $7 \mathrm{~b}$ ). Reactions studied in an $\mathrm{MS}^{4}$ experiment were $\mathrm{MH}^{+} \rightarrow b_{4} \rightarrow a_{1} \rightarrow$ fragments (Figure 7c). All three CID spectra of tyrosine immonium ions are identical, although the experiments are different. Ions of $\mathrm{m} / \mathrm{z} 119$ were observed to be formed by loss of $\mathrm{NH}_{3}$ and ions of $m / z 107$ were formed by loss of $\mathrm{HN}=\mathrm{CH}_{2}$.

\section{Discussion}

The ion-retarding system incorporated into the interface reported here comprises three cylindrical lenses and was designed with computer support to provide deceleration through a ratio in excess of 330:1. A three lens system for extracting and refocusing ions out of the collision cell also is important for improved transmission, especially when collisions occur at low energy.

Although the floatable collision-chemical ionization cell and the additional grounded collision cell provide capabilities for new kinds of experiments on four- sector analyzers, the most important feature of the interface is its enhanced ion transmission at low to intermediate energies. This has facilitated a variety of experiments that involve energy-dependent ion molecule collisions and/or reactions. In addition to neutralization-chemical reionization illustrated here with renin substrate tetradecapeptide, we also have used the interface for H/D exchange [41], target capture [6], ionization of neutral peptides released from proton-bound dimers [42], charge sign inversion [7], and dissection of entropy effects in proton-bound dimers $[6,43]$.

\section{Acknowledgment}

This work was supported in part by a grant from the National Science Foundation.

\section{References}

1. Hunt, D. F.; Shabanowitz, J.; Yates, J. R. J. Chem. Soc. Chem. Commum. 1987, 548-550; Lebrilla, C. B.; Wang, D. T. S.; Mizoguchi, T. J.; McIver, R. T., Jr. J. Am. Chem. Soc. 1989, 111, 8593-8598; Martin, S. A.; Hill, J. A.; Kittrell, C.; Biemann, K. I. Am. Soc. Mass Spectrom. 1990, 1, 107-109. Williams, E. R.; Furlong, J. J. P.; McLafferty, F. W. I. Am. Soc. Mass Spectrom. 1990, 1, 288-294.

2. Cody, R. B.; Freiser, B. S. Anal. Chem. 1987, 59, 1054-1056; Wang, B.; McLafferty, F. W. Org. Mass Spectrom. 1990, 25, 554-556; Aberth, W.; Burlingame, A. L. In Biological Mass Spectrometry; Burlingame, A. L.; McCloskey, J. A., Eds.; Elsevier: Amsterdam, 1990; pp 217-220.

3. Mabud, M. A.; DeKrey, M. J.; Cooks, R. G. Int. J. Mass Spectrom. Ion. Processes 1985, 67, 285-294; Cooks, R. G.; Ast, T.; Mabud, M. A. Int. J. Mass Spectrom. Ion Processes 1990, 100, 209-265; Wright, A. D.; Despreyroux, D.; Jennings, K. R.; Evans, S. J.; Riddoch, A. Org. Mass Spectrom. 1992, 27, 525-526.

4. Orlando, R.; Wu, Z.; Fenselau, C.; Cotter, R. J. Int. I. Mass Spectrom. Ion Processes 1991, 111, 27-40; Orlando, R; Fenselau, C.; Cotter, R. J. I. Am. Soc. Mass Spectrom. 1991, 2, 189-197.

5. Orlando, R.; Fenselau, C.; Cotter, R. J. J. Am. Chem. Soc. 1990 , $112,5747-5749$.

6. Wu, Z.; Fenselau, C. Rapid Commun. Mass Spectrom. 1994, 8, 777-780; Wu, Z.; Fenselau, C. Tetrahedron 1993, 49, 9197-9206. Cheng, X., Wu, Z.; Fenselau, C. I. Am. Chem. Soc. 1993, 115, 4844-4848; Cheng, X.; Fenselau, C. I. Am. Chem. Soc. 1993, $115,10327-10333$.

7. Fenselau, C. In Biological Mass Spectrometry; Matsuo, T.; Caprioli, R. M.; Gross, M. L.; Seyama, Y., Eds.; Wiley: Chichester, 1994; pp 129-146.

8. Harting, E.; Read, F. H. Electrostatic Lenses; Elsevier Scientific: Amsterdam, 1976.

9. Vestal, M. L.; Blakley, C. R.; Ryan, P. W.; Futrell, J. H. Rev. Sci. Instrum. 1976, 47, 15-26.

10. McLafferty, F. W.; Todd, P. J.; McGilvery, D. C.; Baldwin, M. A. J. Am. Chem. Soc. 1980, 102, 3360-3363; Todd, P. J.; McGilvery, D. C.; Baldwin, M. A.; McLafferty, F. W. In Tandem Mass Spectrometry; McLafferty, F. W., Ed.; Wiley: New York, 1983; pp 271-286.

11. Ervin, K. M.; Armentrout, P. B. J. Chem. Phys. 1985, 83, 166-189.

12. Shukla, A. K.; Anderson, S. G.; Howard, S. L.; Sohlberg, K. W.; Futrell, J. H. Int. I. Mass Spectrom. Ion Processes 1988, 86 , 61-82. 
13. Suter, M. J.-F.; Stepnowski, R. M.; Schlunegger, U. P. Rapid Commun. Mass Spectrom. 1989, 3, 417-419.

14. Kemper, P. R.; Bowers, M. T. J. Am. Soc. Mass Spectrom. 1990, 1, 197-207.

15. O'Conner, P. J.; Leroi, G. E.; Allision, J. J. Am. Soc. Mass Spectrom. 1991, 2, 322-335.

16. Turecek, F.; Gu, M.; Shaffer, S. A. J. J. Am. Soc. Mass Spectrom. 1992, 3, 493-501.

17. Lyon, P. A.; Hunt, S. L.; Evans, S.; Tudge, H. Proceedings of the 34th ASMS Conference on Mass Spectrometry; Cincinnati, $\mathrm{OH}, 1986$; pp 162-163.

18. Ishihara, M.; Matsuo, T. Nucl. Instr. Meth. Phys. Res. 1992, $B 70,445-447$.

19. Yu, W.; Martin, S. A. J. Am. Soc. Mass Spectrom. 1994, 5 , 460-469.

20. Matsuo, T.; Ishihara, M.; Martin, S. A.; Biemann, K. Int. I. Mass Spectrom. Ion Processes 1988, 86, 83-87.

21. Read, F. M. J. Phys. 1971, E4, 562-564.

22. Ishihara, M.; Matsuo, T. Proceedings of the 40th ASMS Conference on Mass Spectrometry; Washington, DC, 1992; pp 249-250.

23. Biemann, K. Biomed. Environ. Mass Spectrom. 1988, 16, 99-111; Biemann, K. In Methods in Enzymology; McCloskey, J. A., Ed.; Academic Press: San Diego, 1990; Vol. 193, pp 99-111.

24. Johnson, R. S.; Martin, S. A.; Biemann K. Int. J. Mass Spectrom. Ion Processes 1988, 86, 137-154.

25. Hunt, D. F.; Yates, J. R., III, Shabanowitz, J.; Winston, S.; Hauer, C. R. Proc. Nat. Acad. Sci. USA 1986, 83, 6233-6237; Alexander, A. J.; Boyd, R. K. Int. J. Mass Spectrom. Ion Processes 1989, 90, 211-240.

26. Johnson, R. S.; Martin, S. A.; Biemann, K. Anal. Chem. 1987, $59,2621-2625$.

27. Bean, M. F.; Carr, S. A.; Thorne, G. C.; Reilly, M. F.; Gaskell, S. J. Anal. Chem. 1991, 63, 1473-1481.

28. Martin, S. A.; Johnson, R. S.; Costello, C. E.; Biemann, K. In The Analysis of Peptides and Proteins by Mnss Spectrontetry; McNeal, C. J., Ed.; Wiley: New York, 1988; pp 135-151.
29. Alexander, A. J.; Thibault, P.; Boyd, R. K. Rapid Commun. Mass Spectrom. 1989, 3, 30-34.

30. Wu, Z.; Fenselau, C. Rapid Commun. Mass Spectrom. 1992, 6, 403-405.

31. Bordas-Nagy, J.; Despeyroux, D.; Jennings, K. R. J. Am. Soc. Mass Spectrom. 1992, 3, 502-514.

32. Gellene, G. I.; Porter, R. F. Acc. Chem. Res. 1983, 16, 200-207; Wesdemoitis, C.; McLarfferty, F. W. Chem. Rev. 1987, 87, 485-500; Terlouw, J. K.; Schwartz, H. Angevv. Chem. Int. Ed. Engl. 1987, 26, 805-815; Holmes, J. L. Adv. Mass Spectrom. 1989, 11A, 53-79.

33. Davis, S. C.; Derrick, P. J.; Ottinger, C. Z. Naturforsch. A: Phys. Sci. 1990, 45, 1151-1157.

34. Budzikiewicz, H.; Djerassi, C.; Williams, D. H. Mass Spectrometry of Organic Compounds; Holden-Day: San Francisco, 1967; pp 336-366.

35. Lias, S. G.; Bartmess, J. E.; Liebman, J. F.; Holmes, J. L.; Levin, R. D.; Mallard, W. G. J. Phys. Chem. Ref. Data 1988, 17, Suppl. 1.

36. Wu, Z.; Fenselau, C. J. Am. Soc. Mass Spectrom. 1992, 3, 863-866.

37. Nourse, B. D.; Cox, K. A.; Morand, K. L.; Cooks, R. G. J. Am. Chem. Soc. 1992, 114, 2010-2016.

38. Tomer, K. B.; Guenat, C. R.; Deterding, L. J. Anal. Chem. 1988, $60,2232-2236$

39. Byrant, D. K.; Orlando, R. Rapid Commun. Mass Spectrom. 1991, 5, 124-127.

40. Wu, Z.; Bordas-Nagy, J.; Fenselau, C. Org. Mass Spectrom. 1991, 26, 908-911.

41. Cheng, X.; Fenselau, C. Int. I. Mass Spectrom. Ion Processes 1992, 122, 109-119.

42. Wu, Z.; Fenselau, C. Org. Mass Spectrom. 1993, 28, 1034-1040.

43. Kaltashov, I.; Fabris, D.; Fenselau, C. Proceedings of the 42 nd ASMS Conference on Mass Spectrometry; Chicago, IL, 1994. 